Article

\title{
Public Perception of Urban Air Quality Using Volunteered Geographic Information Services
}

\author{
Sonja Grossberndt ${ }^{1, *}$, Philipp Schneider ${ }^{2}$, Hai-Ying Liu ${ }^{1}$, Mirjam F. Fredriksen ${ }^{3}$, Nuria Castell ${ }^{2}$, \\ Panagiota Syropoulou ${ }^{4}$ and Alena Bartoňová ${ }^{2}$ \\ ${ }^{1}$ Environmental Impacts and Sustainability Department, NILU-Norwegian Institute for Air Research, 2027 Kjeller, Norway; \\ E-Mails: sg@nilu.no (S.G.), hyl@nilu.no (H.-Y.L.) \\ 2 Urban Environment and Industry Department, NILU-Norwegian Institute for Air Research, 2027 Kjeller, Norway; \\ E-Mails: ps@nilu.no (P.S.),ncb@nilu.no (N.C.), aba@nilu.no (A.B.) \\ ${ }^{3}$ Software and Hardware Development Department, NILU-Norwegian Institute for Air Research, 2027 Kjeller, Norway; \\ E-Mail: mff@nilu.no (M.F.F.) \\ ${ }^{4}$ DRAXIS Environmental S.A., 54655 Thessaloniki, Greece; E-Mail: syropoulou.p@draxis.gr \\ * Corresponding author
}

Submitted: 15 April 2020 | Accepted: 20 July 2020 | Published: 14 October 2020

\begin{abstract}
Investigating perceived air quality $(A Q)$ in urban areas is a rather new topic of interest. Papers presenting results from studies on perception of $A Q$ have thus far focused on the individual characteristics leading to a certain $A Q$ perception or have compared personal perception with on-site measurements. Here we present a novel approach, namely applying volunteered geographic information (VGI) technologies in urban AQ monitoring. We present two smartphone applications that have been developed and applied in two EU projects (FP7 CITI-SENSE and H2020 hackAIR) to obtain citizens' perception of $\mathrm{AQ}$. We focus on observations reported through the smartphone apps for the greater Oslo area in Norway. In order to evaluate whether the reports on perceived $A Q$ contain information about the actual spatial patterns of $A Q$, we carried out a comparison of the perception data against the output from the high-resolution urban AQ model EPISODE. The results indicate an association between modelled annual average pollutant concentrations and the provided perception reports. This demonstrates that the spatial patterns of perceived AQ are not entirely random but follow to some extent what would be expected due to proximity of emission sources and transport. This information shows that VGI about citizens' perception of $A Q$ has the potential to identify areas with low environmental quality for urban development.
\end{abstract}

\section{Keywords}

air quality; CITI-SENSE; hackAIR; public perception; smartphone applications; volunteered geographic information

\section{Issue}

This article is part of the issue "The City of Digital Social Innovators" edited by Chiara Certomà (Ghent University, Belgium), Antonella Passani (T6-Ecosystems, Italy) and Mark Dyer (University of Waikato, New Zealand).

(C) 2020 by the authors; licensee Cogitatio (Lisbon, Portugal). This article is licensed under a Creative Commons Attribution 4.0 International License (CC BY).

\section{Introduction}

Investigating perceived air pollution in urban areas has caught the interest of researchers in the last two decades as the relationship between air pollution and adverse health effects has become clearer (Bickerstaff \& Walker, 2001; Brody, Peck, \& Highfield, 2004).
Despite significant improvements in air quality (AQ) in Western Europe, many European areas still struggle to reduce outdoor concentrations of particulate matter (PM) and nitrogen dioxide $\left(\mathrm{NO}_{2}\right.$; European Environmental Agency, 2018). The main local sources of air pollution in urban areas are road traffic, industry and domestic combustion (Gulia, Nagendra, Khare, \& 
Khanna, 2015). There is evidence that health effects such as strokes, heart diseases, acute and chronic respiratory diseases, including lung cancer and asthma, are linked to exposure to $\mathrm{PM}$ or $\mathrm{NO}_{2}$ caused by air pollution (World Health Organization, 2016). The high number of premature deaths and years of life loss due to the effects of air pollution indicates the need for both further measures to reduce air pollution and to continuously raise public awareness and empower citizens to protect their health from the adverse effects of air pollution.

Evidence of adverse health effects of air pollution have not gone unnoticed by European citizens. In a recent Eurobarometer survey, $46 \%$ of the respondents indicated that air pollution is one of the most important environmental issues and $47 \%$ think that $A Q$ has deteriorated in their country over the last 10 years (European Commission, 2017). This survey indicates that European citizens are aware of air pollution and perceive air pollution as a threat to health and well-being.

In the last decade, the application of volunteered geographic information (VGI) technologies in AQ monitoring has undergone a rapid development. In addition to for example exploiting VGI for applications such as emission estimates (López-Aparicio, Vogt, Schneider, Kahila-Tani, \& Broberg, 2017), the application of VGI in the $A Q$ field has seen substantial growth related to the emergence of low-cost $A Q$ sensors. A large number of low-cost $A Q$ monitoring sensor systems are now available on the market (Castell et al., 2017) which allow interested individuals to measure AQ instantaneously, providing information that can be used for private purposes or for the greater good (Castell et al., 2018), e.g., for creating $A Q$ maps at high spatial resolution (Schneider et al., 2017, 2018; Wesseling et al., 2019). The rise of these measurement systems has facilitated measuring urban $A Q$ at many different locations not covered by official monitoring stations. With the help of low-cost AQ monitoring sensor systems, lay people can perform measurements without the years of training needed to handle the technical equipment. Despite the fact that this technology is generally not yet mature enough to deliver data quality comparable to reference equipment (Liu, Schneider, Haugen, \& Vogt, 2019) and still often requires a certain amount of data processing (Schneider et al., 2019), these instruments are still suitable to engage with citizens in $A Q$ monitoring. They are instrumental for: (i) raising awareness about air pollution in the broader population (Sîrbu et al., 2015); (ii) educating and involving citizens in local communities (Turrini, Dörler, Richter, Heigl, \& Bonn, 2018); (iii) bringing citizens closer together with policy and decision-makers (Turrini et al., 2018); and (iv) setting up larger networks of low-cost AQ monitoring sensor systems (Lisjak, Schade, \& Kotsev, 2017; Wesseling et al., 2019).

Many projects and initiatives have been carried out in the last years, using low-cost technologies to monitor urban AQ (e.g., EU FP7 CITI-SENSE [Liu, Kobernus, Broday, \& Bartonova, 2014], EU H2020 hackAIR [Kosmidis et al., 2018], H2020 iSCAPE [Mahajan et al., 2020], or Sensor.Community [https://sensor.community/en]). They mostly targeted collecting quantitative physical evidence of air pollution. We believe that qualitative information contributed by citizens can provide useful complementary knowledge. We also believe that to successfully address air pollution, physical data needs to be complemented by taking into account people's attitudes and perceptions. We have collected qualitative VGI information on $A Q$-reporting personal perception of the surrounding air through smartphone applications (apps).

To the authors' knowledge, there are two main categories of studies on perception of urban air pollution per today. The first category investigates individual characteristics that lead to a certain perception of air pollution (e.g., Mayer, O'Connor Shelley, Chiricos, \& Gertz, 2017; Oltra \& Sala, 2018). These studies investigate if perception of air pollution is influenced by factors such as risk beliefs, perceived threat or risks of air pollution, coping options and self-protective actions (Mayer et al., 2017; Oltra \& Sala, 2018).

Studies in the second category compare AQ perception of volunteers with actual measurement results (e.g., Deguen, Padilla, Padilla, \& Kihal-Talantikite, 2017; Pantavou, Lykoudis, \& Psiloglou, 2017; Pantavou, Psiloglou, Lykoudis, Mavrakis, \& Nikolopoulos, 2018). Some of those studies comprise of a quite complex study design, collecting, e.g., meteorological data, $A Q$ data, information on the volunteers' age, gender and health status and their perception of the $A Q$ at a specific geographic area over a specific time period. Some of the volunteers were even asked more specifically about their concern about $A Q$, level of support for certain $A Q$ measures, or how informed they felt about certain measures (Schmitz et al., 2018). In another study additional individual characteristics such as family status, education level, occupation, housing area or commuting habits were put into relation with air pollution measurements (Deguen et al., 2017). In summary the results from both, the first and second category studies show that $A Q$ perception depends on a broad range of internal and external factors and that ambient $A Q$ is a multidimensional issue that influences people differently.

Here we introduce a novel third category, applying VGI technologies-i.e., smartphone apps-for reporting $A Q$ perceptions. These activities have been carried out in the EU FP7 CITI-SENSE project (2012-2016) and the EU H2020 hackAIR project (2016-2018). Both projects engaged volunteers in $A Q$ measurements in several places in Europe by reporting both sensor measurements and own perceptions of $A Q$. In this article, we look closer at the $A Q$ perceptions reported by volunteers from the greater Oslo area in Norway and compare the perception data with data from reference $A Q$ measurements and models. We discuss the results and conclude with recommendations of potential use of VGI methods for reporting $A Q$ perceptions. 


\section{Study Area and Approach}

Our study has its origin within the project CITISENSE (2012-2016). CITI-SENSE developed 'Citizens' Observatories' based on a collaborative concept with a focus on citizens' empowerment to influence their community policy in decision-making regarding $A Q$ issues (Liu et al, 2014). As a part of the empowerment process, we aimed to raise awareness of $A Q$ problems amongst citizens. We developed different tools, amongst them a smartphone app (CityAir app; see Figure 1, left), enabling people to indicate their perception of the surrounding $A Q$ through a four-colour code. After downloading the app from Google Play or the App Store, the user could generate a user profile containing sociodemographic information (i.e., gender, age and education level). However, this information was not required in order to use the app. AQ perception could be reported by positioning a coloured marker on a map as provided by the smartphone's GPS location. The user could choose between four colours (green = 'very good,' yellow $=$ 'good,' orange $=$ 'poor,' red $=$ 'very poor') to indicate how they perceived the $A Q$ at their location. When choosing the colour yellow, orange or red, indicating that the perceived AQ was other than 'very good,' a second window would open where the user could select one or several of the perceived air pollution sources (i.e., traffic, industry, residential heating, port/harbour, dust, smoke, strong odour, pollen, others and 'I do not know'). The user could also leave a comment. The CityAir app also allowed the user to see what other users reported. Every time a user left a marker or a comment, the following information was stored locally on the phone and

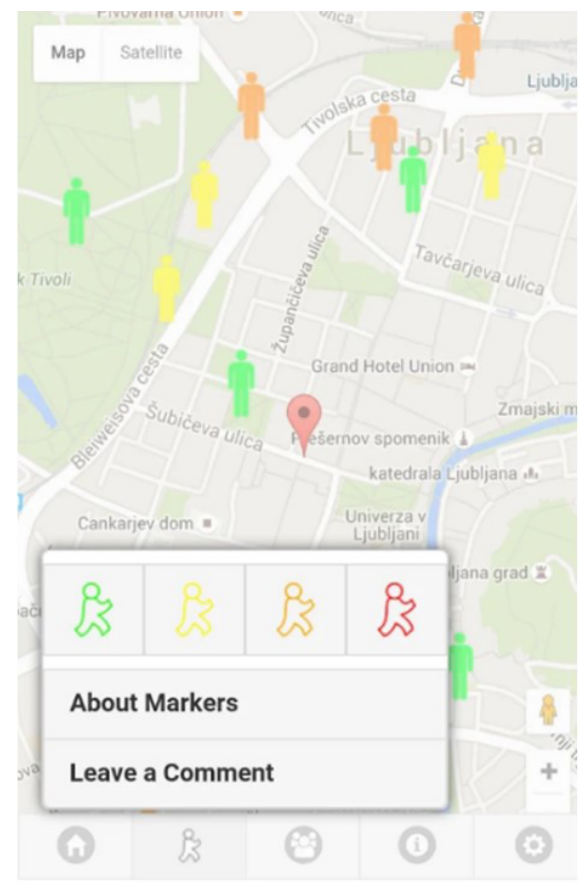

was later uploaded and stored to the cloud service we used in the project: colour of marker, GPS location, date, gender, age, education level (if available), perceived air pollution source(s) and any free-text comments. In case the user did not have Internet connection while reporting, the information was uploaded to the server as soon as the phone had Internet connection.

Public perception data was collected through the CityAir app between 1st September 2015 and 31st October 2016. Users were recruited from participants at the European Green Mobility week ( $N \approx 150$ people), a scientific breakfast event $(N \approx 70)$, leaflets in 21 public libraries in Oslo, distribution of leaflets to three schools and 17 kindergartens participating in other elements of the project, promotion of the app on Facebook, Twitter and web pages, information to volunteers who measured $A Q(N \approx 40)$, and through a dedicated four-day social media campaign in collaboration with research partners and a patient organization.

A similar app was used within the EU H2O2O hackAIR project, an open technology platform for anyone to access, collect and improve $A Q$ information in Europe. The main aim of the hackAIR project was to raise public awareness about the problem of air pollution and at the same time as motivating citizens to monitor outdoor $A Q$ on their own (Kosmidis et al., 2018). This could be done through building their own low-cost $A Q$ sensors, taking a picture of the sky (Spyromitros-Xioufis et al., 2018) or reporting subjective perceptions of the surrounding $A Q$. The option of reporting personal AQ perception was part of the hackAIR smartphone app (Figure 1, right). In order to submit AQ perceptions, the user had to go to the 'perception of $A Q^{\prime}$ ' tab at the smartphone app,

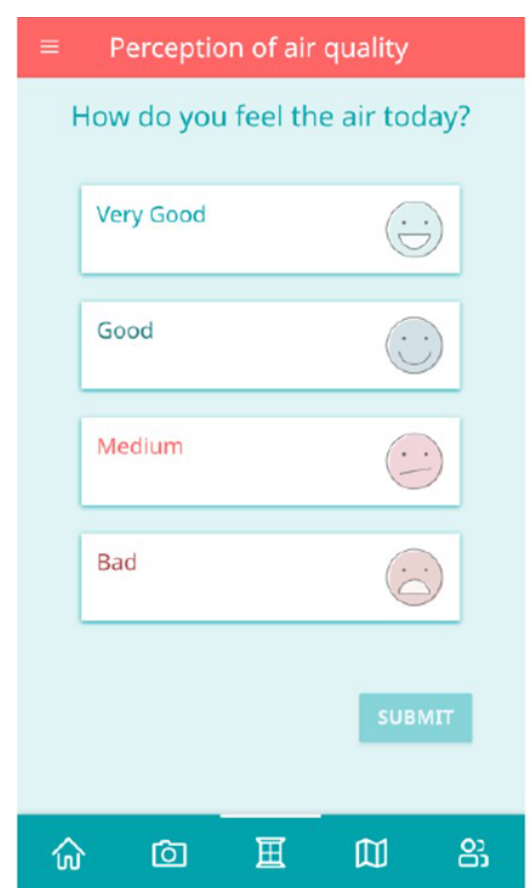

Figure 1. From left to right: Screenshot of the CityAir app and the functionality to report personal perception in the hackAIR app. 
turn on GPS location and choose one of four categories: 'very good,' 'good,' 'medium' or 'bad.' By choosing one of these categories and clicking the 'submit' button, the perception was automatically logged and appeared on the map at the position provided by the smartphone's GPS. The anonymised observation could be seen by other hackAIR users on a map.

$A Q$ perception has been reported through the hackAIR app between 9 February 2018 and 8 February 2019. Participants were recruited during 'build-your-own-AQsensor' workshops (115 persons) and through social media campaigns (Facebook event and Facebook video).

Both CityAir and hackAIR smartphone apps were developed for Android and iPhone and were made available through Google Play and App Store where they are still available for download today.

In this article, we address the perceptions of volunteers in the greater Oslo area in Norway, obtained from the CITI-SENSE and hackAIR projects. For the greater Oslo area, we have access to high-resolution $(100 \times 100 \mathrm{~m})$ output from the state-of-the-art urban-scale air pollution dispersion model EPISODE (Hamer et al., 2019), and we are able to match the obtained VGI data with the model results using the GPS position. Using the EPISODE model allows us to obtain $A Q$ information at any spatial location in the city. Comparing the collected data with observations from $A Q$ monitoring stations would limit the comparison substantially because the comparison could only be carried out in the immediate vicinity of the station, thus eliminating the vast majority of perception samples from further analysis. We use this data to perform a basic comparison of the qualitative perceptions against annual average estimated air pollution in order to investigate to what extent the spatial patterns of subjective perceptions align with modelled $A Q$ estimates. More specifically, we have extracted the annual average modelled concentration value for each of the three main pollutants $\left(\mathrm{NO}_{2}, \mathrm{PM}_{2.5}\right.$, and $\left.\mathrm{PM}_{10}\right)$ at each location where perceptions were reported. The actual annual average is obtained as a bilinear interpolation between the neighbouring four grid cells at $100 \times 100 \mathrm{~m}$ resolution. We then plotted and summarised the values for each perception class.

\section{Statistical Analysis}

In this article, we present the results of two data collection studies, the first using the CityAir app and the second using the hackAIR app. The classification of pollution levels consists of four classes in both apps, though the hackAIR app uses 'medium' where CityAir uses 'poor' and 'bad' where CityAir uses 'very poor.' Other differences are that the CityAir app allows the user to register (i) demographics information and (ii) which source of pollution they think contributes to reduced $A Q$.

Sampling periods in this article are for CityAir, September 2015-October 2016, and for hackAIR, February 2018-February 2019.
On the basis of the CityAir app data, we would like to establish if the perceptions reported through the app differ based on gender, age and education level, using a contingency table approach; this is to ascertain if the subsequent analysis of association between the perception and $A Q$ needs to be controlled for these factors.

For both sampling periods, we assigned to each perception registration the annual average pollution level corresponding to the year of the registration. This average was calculated by the EPISODE model.

For both studies, we investigate whether the perception reported through the apps correlates with a longterm average air pollution model. We have limited our work to an analysis of variance of a hypothesis 'does the air pollution differ between perception classes' for each air pollutant separately, using pairwise Wilcoxon Rank Sum tests. We then tested the null-hypothesis that average pollution levels are the same for all perception classes.

\section{Results}

\subsection{CityAir App}

\subsubsection{Demographics}

332 reports were available for analysis. However, we used the parameters 'male,' '1970,' and 'high school' as demographic standard settings that people could but did not have to change, and 'traffic' as a pre-set pollution source, that could be changed. For demographic analysis, we had to de-validate cases recording only the three pre-selected categories to make sure only valid cases remained. Thus, we had 241 valid reports for age, gender and education level that could be used for the sociodemographic description of the population involved.

The CityAir app users were $55 \%$ male and $45 \%$ female. The app was more commonly used by younger people: $65 \%$ of users were born between 1970 and 1989. About one third of the participants were born before 1970, more than $60 \%$ between 1970 and 1990. Participants were rather well-educated: $62 \%$ of the participants held a university degree and $28 \%$ a PhD; only $10 \%$ of the participants have not completed university (Figure 2).

In our sample, we had more younger men (born 1970-1989) than women and more older women (born 1960-1969) than men. More men than women reported high school and university as highest level of education, whereas more women than men held a PhD degree (Figure 3).

A contingency table analysis (perception vs education, perception vs gender, perception vs decade of birth) did not reveal any significant differences (Table 1 ).

\subsubsection{AQ Perception}

Since there do not seem to be any statistically significant differences in reporting based on education level, gen- 


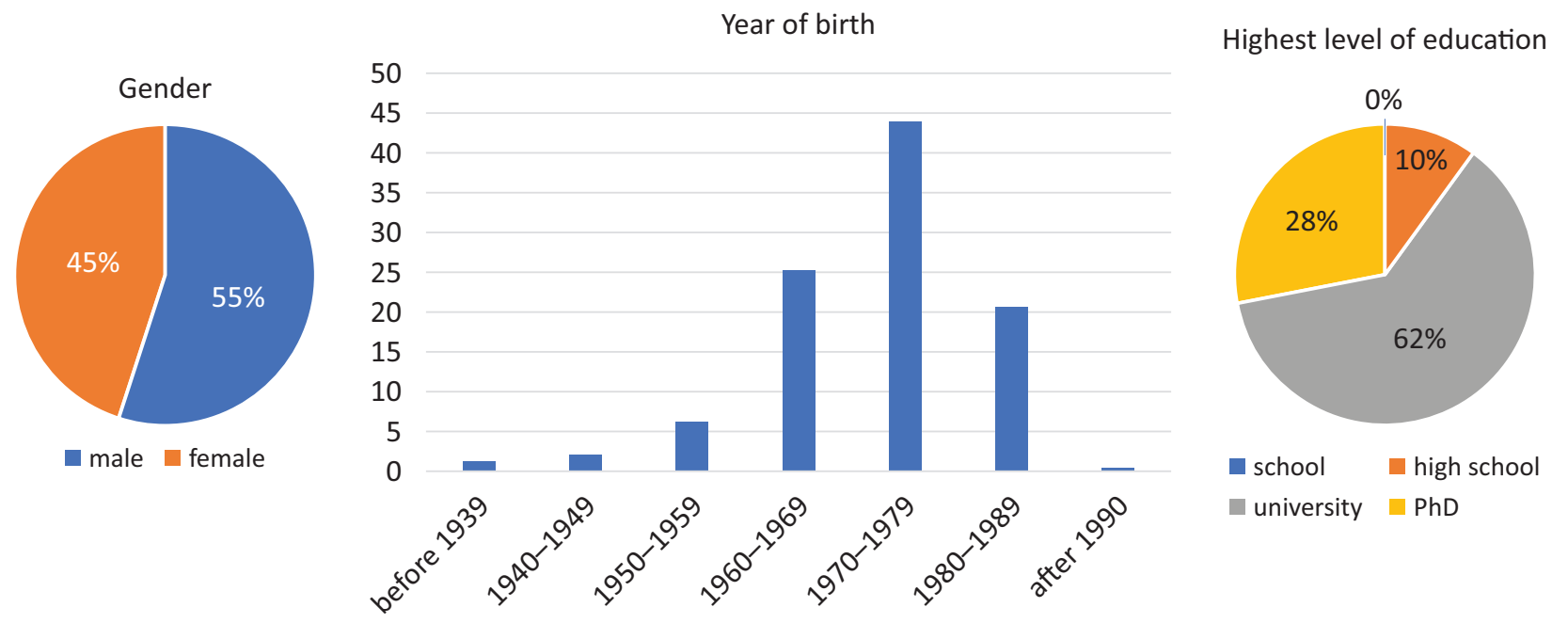

Figure 2. Characteristics of the CityAir users (in \%).

Year of birth by gender

80

70

60

50

40

30

20

10

0

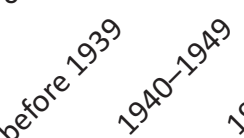<smiles>O=COC1CCCCC1</smiles>

male female
Highest level of education by gender

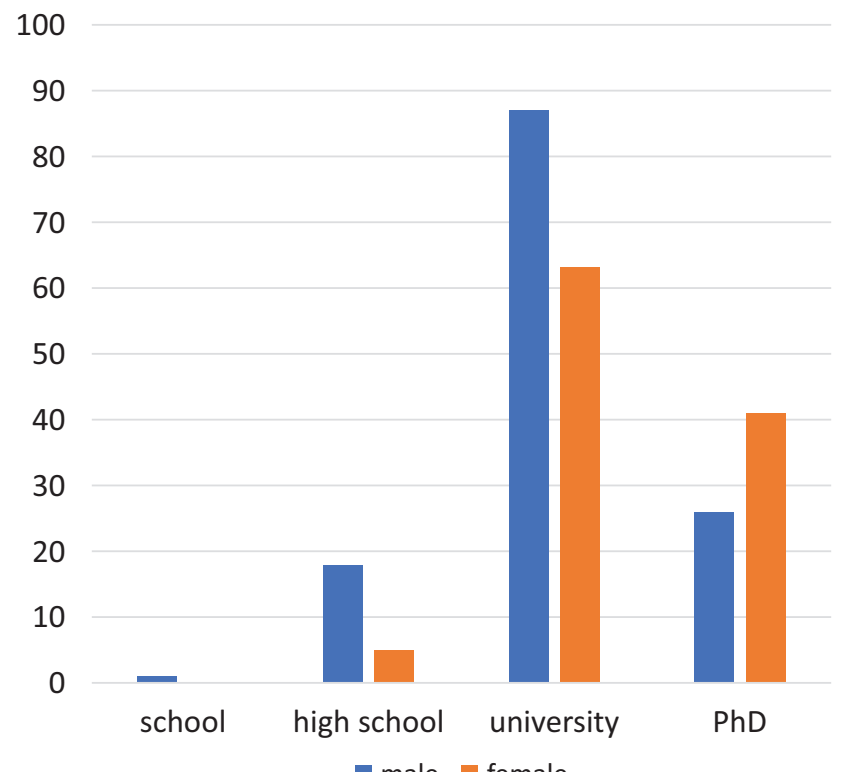

Figure 3. From left to right: Distribution of age and gender and distribution of education level and gender of the CityAir app users.

Table 1. Distribution of perception reporting, by age, gender, and education level $(N=241)$.

\begin{tabular}{|c|c|c|c|c|c|c|c|c|c|}
\hline \multirow[b]{2}{*}{ Perception } & \multicolumn{4}{|c|}{ Year of birth } & \multicolumn{2}{|c|}{ Gender } & \multicolumn{3}{|c|}{ Education level } \\
\hline & $\begin{array}{c}\text { Before } \\
1960\end{array}$ & 1961-1970 & 1971-1980 & $\begin{array}{l}1981 \text { and } \\
\text { later }\end{array}$ & Male & Female & $\begin{array}{l}\text { School and } \\
\text { high school }\end{array}$ & University & $\mathrm{PhD}$ \\
\hline Very good & 16 & 28 & 50 & 28 & 70 & 52 & 10 & 77 & 35 \\
\hline Good & 4 & 20 & 23 & 12 & 26 & 33 & 6 & 40 & 13 \\
\hline Poor & 1 & 5 & 21 & 7 & 21 & 13 & 5 & 18 & 11 \\
\hline Very poor & 2 & 8 & 12 & 4 & 15 & 11 & 2 & 16 & 8 \\
\hline
\end{tabular}

Note: Test by chi-square revealed statistics values chi-square $=11.28$ ( 9 d.f.) for relation with age category, 4.03 (6 d.f.) with education and 3.83 ( 3 d.f.), all of them not significantly different from zero $(p=0,05)$. 
der or age, we used all 332 reports for the analysis relating perception to $\mathrm{AQ}$. $75 \%$ of the participants assessed the greater Oslo area AQ as 'good' (52\% 'very good,' 23\% 'good'), only $21 \%$ reported 'poor' AQ in Oslo (13\% 'poor,' $8 \%$ 'very poor'; see Figure 4).

We obtained more perception data in autumn 2015, due to the first recruitment activities. $A$ bad $A Q$ episode in February 2016 resulted in more frequent use of the CityAir app. We intensified our recruitment activities in April, followed by a Facebook event in May, which led to a higher number in reports, and a newspaper article on the project was published in September.

\subsubsection{Perceived Air Pollution Sources}

Users could also indicate what pollution source(s) they thought contributed to the bad AQ. Multiple answers were possible. In first place was 'traffic' with 115 reports, followed by 'dust' with 41 reports. The remaining categories were named less than 20 times, with 'port/harbour' in last place with only two reports (Figure 5). However, note that 'traffic' was a pre-set pollution source, that people could-but did not have tochange. Thus, it cannot be ruled out that the high number of 'traffic' reports could be caused by people who did not change the pre-set pollution source.

\section{2. hackAIR App}

The hackAIR dataset consisted of 204 reports. $55 \%$ of the volunteers reported Oslo $A Q$ as 'very good' ( $N=112$ ) and $32 \%$ as 'good' $(\mathrm{N}=66)$. The designation 'medium' was assigned to the Oslo air by a total number of 25 volunteers $(12 \%)$ and only one volunteer equalling $0 \%$ reported the class 'bad' (Figure 6). It was not required to provide information on gender, age or education when

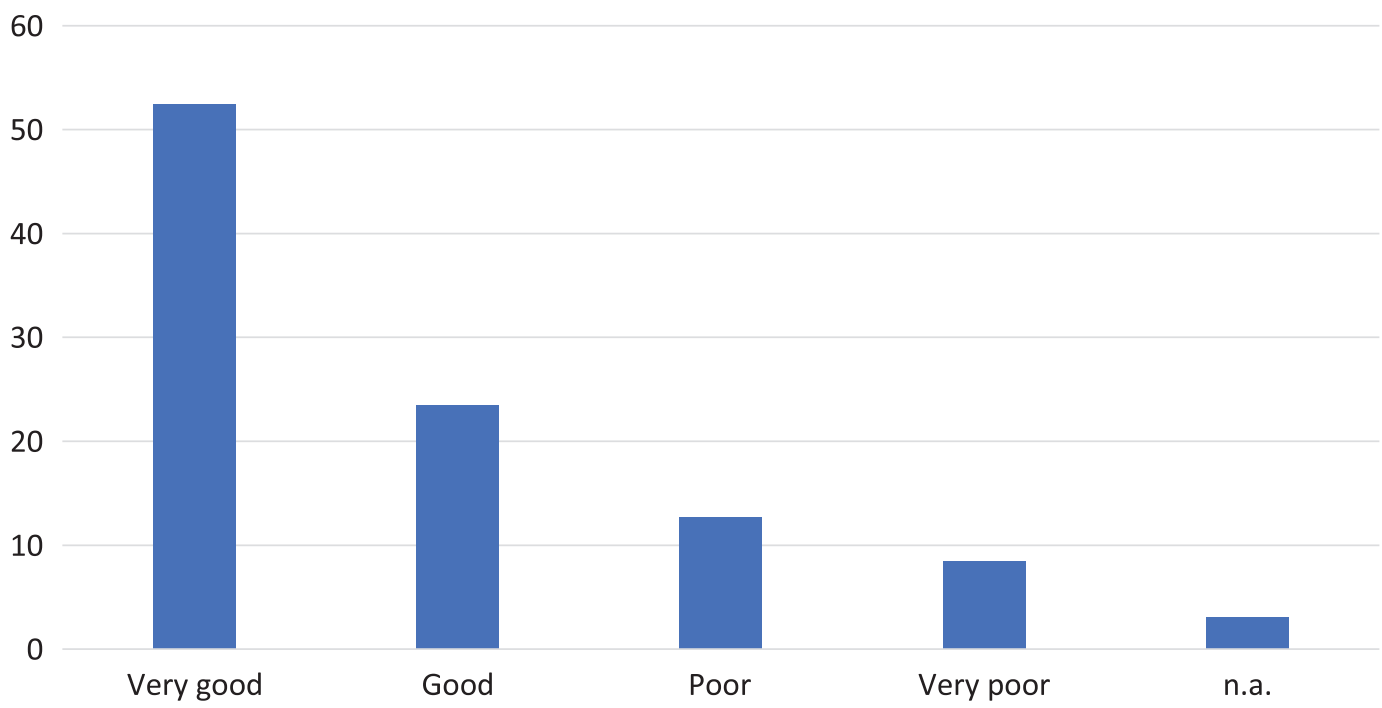

Figure 4. AQ perception of the CityAir app users (in \%).

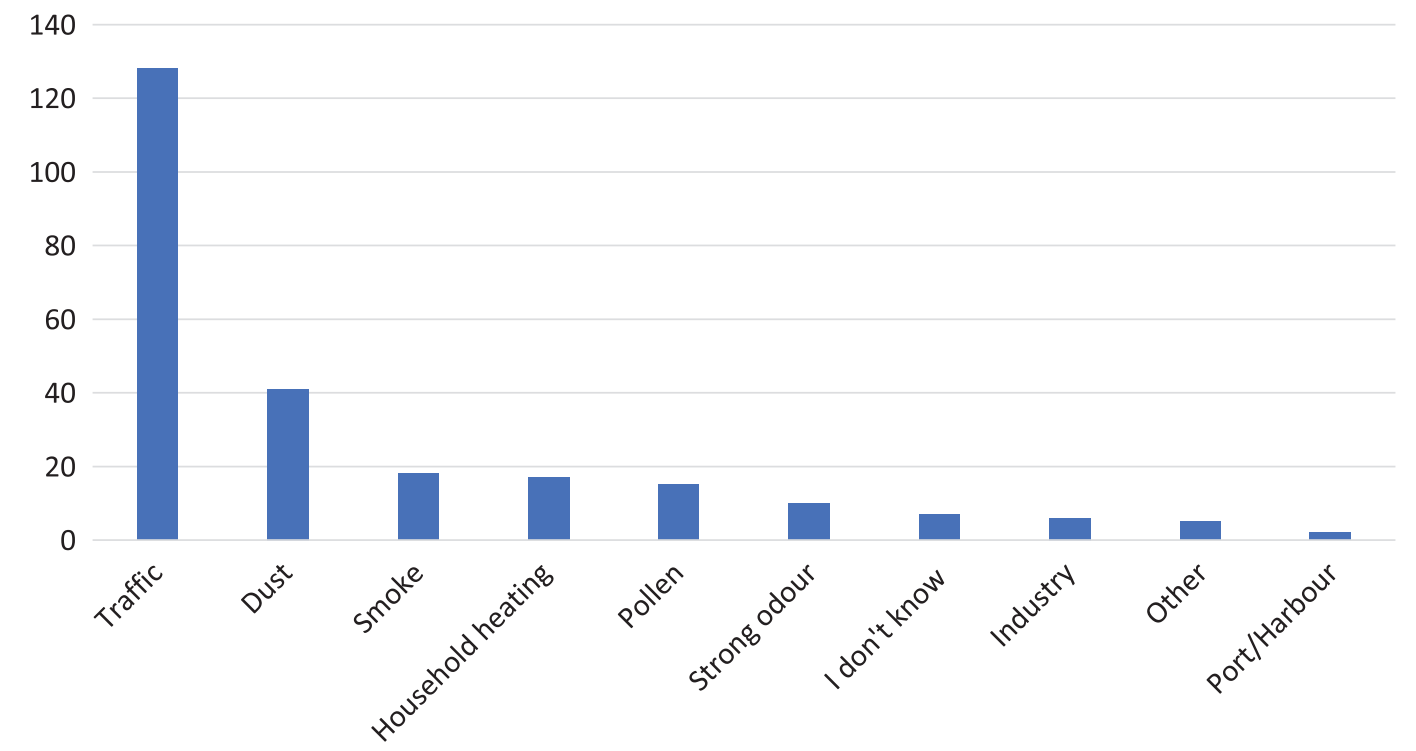

Figure 5. Pollution sources indicated by the CityAir app users. 


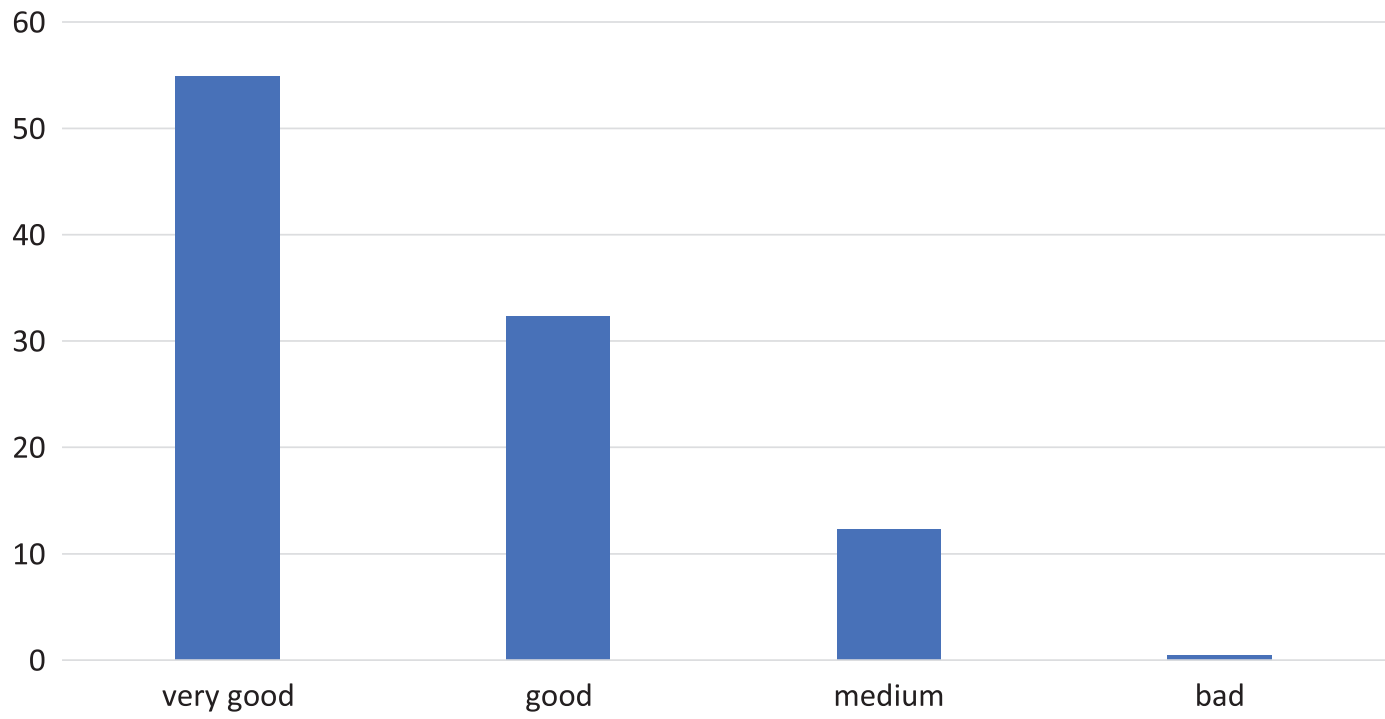

Figure 6. AQ perception of the hackAIR app users (in \%).

logging on to the hackAIR app. Users could also choose not to indicate any pollution sources.

The official hackAIR-launch took place in February 2018 , followed by a number of local workshops in March/April and June 2018, where people could build their own AQ sensors. At these events, we also promoted the use of the hackAIR app to report $A Q$ perceptions. Both occasions resulted in a higher number of reported $A Q$ perceptions. We arranged a Facebook event in June 2018 to promote the use of the hackAIR app. This led to a higher number of observations. In autumn that year, we arranged another round of workshops, followed by a Facebook video to promote the use of the app for reporting personal AQ perceptions. This resulted again in a higher number of perceptions reported through the hackAIR app.

\subsection{Comparison with AQ Estimated by the EPISODE Dispersion Model}

To evaluate whether the reports on perceived $A Q$ from the perception datasets contain information about the actual spatial patterns of $A Q$, we carried out a compari- son of the perception data against the output from the high-resolution urban $A Q$ model EPISODE (Hamer et al., 2019). This complex model has been verified to represent the $A Q$ well both in time and space and it provides point estimates with spatial resolution of down to five meters. The results indicate a relationship between the average modelled pollutant concentrations and the provided perception reports, thus indicating that the spatial patterns of perceived $A Q$ are not entirely random but follow to some extent spatial patterns of $A Q$.

Figure 7 shows modelled annual average concentration fields of $\mathrm{NO}_{2}, \mathrm{PM}_{10}$ and $\mathrm{PM}_{2.5}$ for the greater Oslo area and also indicates the location of the perception reports from both the CITI-SENSE and the hackAIR project. While the vast majority of perception reports was located within the city of Oslo (hotspot slightly north from the map centre), some reports were also received from less densely populated areas outside the city limits.

Figure 8 shows how the average modelled $A Q$ for the three pollutants varies with the four perception classes for the CityAir dataset ( $\mathrm{N}=332$; above) and for the hackAIR dataset $(\mathrm{N}=204$; below).
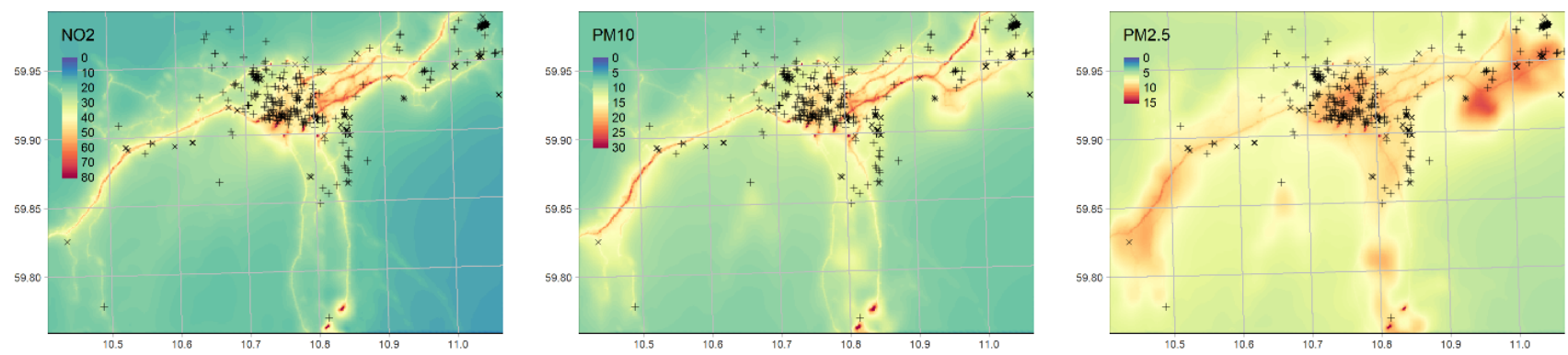

Figure 7. Long-term average concentrations in units of $\mu \mathrm{g} / \mathrm{m}^{3}$ for the greater Oslo area as provided by the EPISODE model (Hamer et al., 2019). Notes: The pollutants $\mathrm{NO}_{2}, \mathrm{PM}_{10}$, and $\mathrm{PM}_{2.5}$ are shown in the left, centre, and right panel, respectively. Locations of the perception reports are marked as + for CityAir and as $x$ for hackAIR. Axes units are degrees latitude and longitude (WGS84). 


\section{CityAir app}
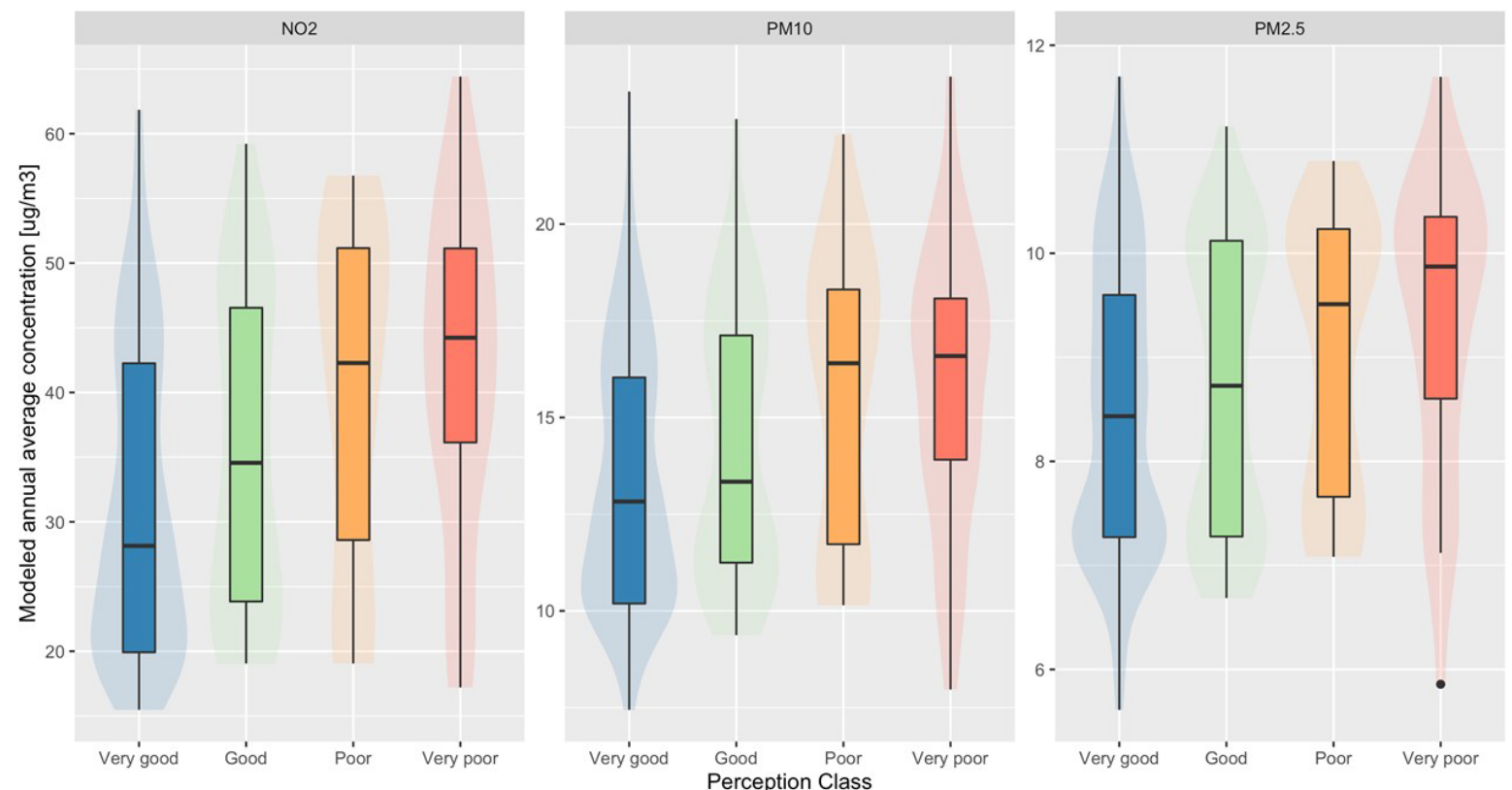

hackAIR app
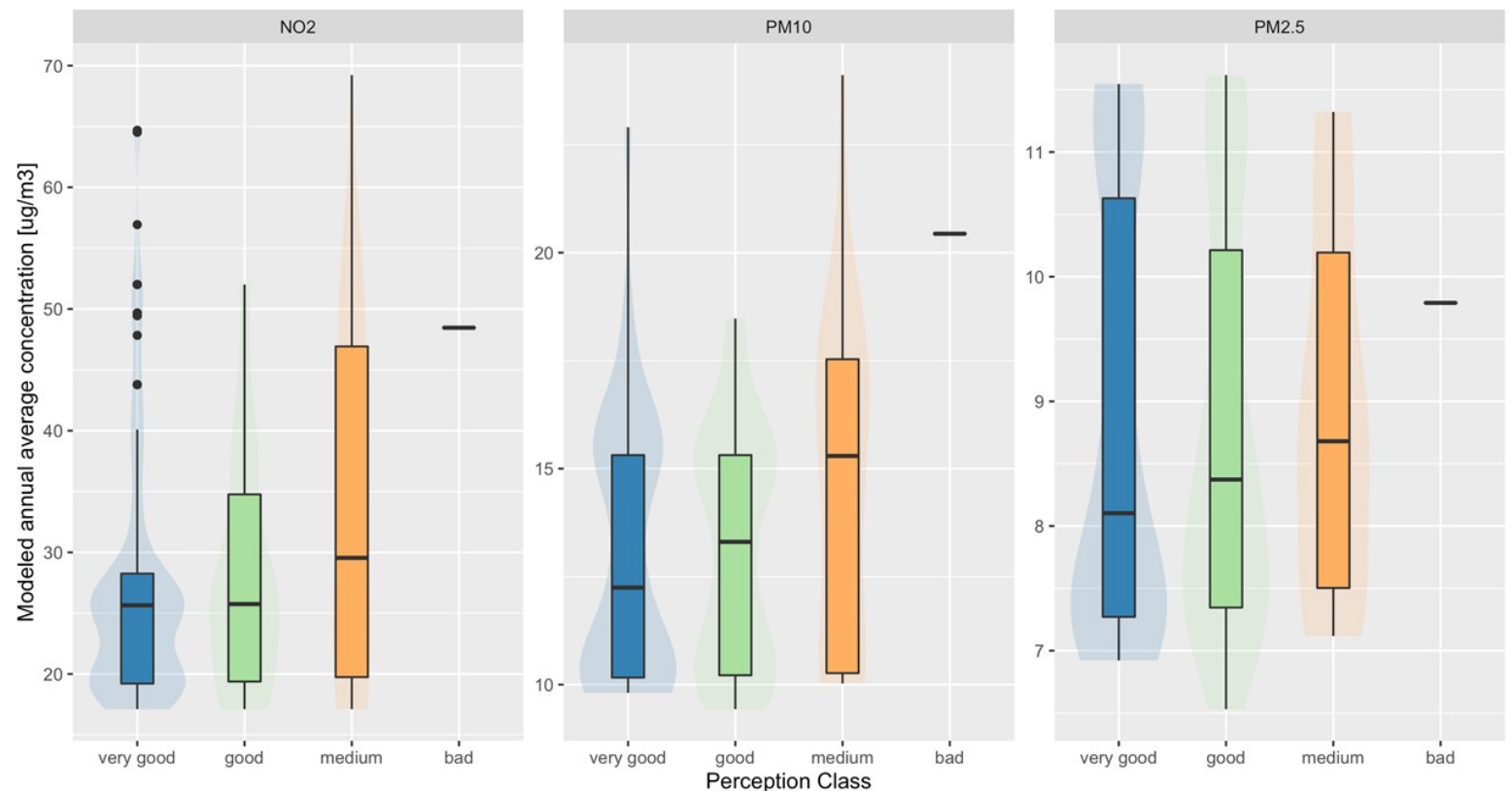

Figure 8. Combined Box- and Violin-plot showing the modelled annual average concentration for $\mathrm{NO}_{2}, \mathrm{PM}_{10}$, and $\mathrm{PM}_{2.5}$, respectively, extracted at the location of the four perception classes used in the CityAir app (above) and the hackAIR app (below). Notes: The slightly transparent areas in the background of the boxplots show the actual underlying distributions. The lower and upper hinges of the boxplots correspond to the 25th and 75th percentiles, whereas the whiskers extend to 1.5 times the interquartile range with any data beyond the whiskers (outliers) plotted individually.

For CityAir, we can observe in all three cases that the median modelled pollution level systematically increases from the 'very good' to the 'very poor' perception class. While there is significant overlap between the individual classes, this shows that on average the reports on perceived $A Q$ match the expected spatial patterns.
For the hackAIR data, not all perception classes are populated with enough samples to calculate the appropriate summary statistics (i.e., the 'bad' class only contains three values) and the computed differences are less significant and prone to higher uncertainties. However, the general pattern of increasing modelled concentra- 
tion levels with perception classes going from 'very good' to 'bad' prevails. One exception can be seen for $\mathrm{NO}_{2}$ where the 'excellent' class has approximately the same median as the 'good' class. This is quite likely a result of the comparatively low number of samples. It is expected that with an increasing number of perception reports, the figure for hackAIR would begin to resemble more clearly the patterns seen in the figure for CityAir (Figure 8).

Table 2 shows the adjusted $p$-values for pairwise Wilcoxon Rank Sum tests and thus gives some indication on which of the differences in class medians shown in Figure 8 are statistically significant. For the CityAir app the 'very good' class is different from nearly all other classes (except for the 'good' class of $\mathrm{PM}_{10}$ and $\mathrm{PM}_{2.5}$ ). The other classes are not statistically significant against each other. For the hackAIR app it is only the 'medium' class for $\mathrm{NO}_{2}$ that is statistically significant from the 'very good' class.

\section{Discussion}

Our results indicate that the perception data have the potential to indicate local $A Q$, in our case measured as an annual average for three pollutants. In urban areas, the most prominent sources of air pollution are local traffic and residential heating. Traffic in particular is likely to contribute to other stressors such as noise, and areas with high traffic load are also likely to lack qualities such as green spaces.

The pilot studies in both the CITI-SENSE and the hackAIR project have not been designed to demonstrate whether or to which degree citizens-as-sensors/VGI can produce useful $A Q$ data. The main purpose was to engage with citizens, raise awareness about $A Q$ and to provide them with a tool to report their own $A Q$ perceptions.

In this article, we look closer at the AQ perceptions reported through VGI tools in the greater Oslo area, and try to understand if there are any patterns that are not related to $A Q$. We observed that both CityAir and hackAIR participants judged the $A Q$ in the greater Oslo area as good. It would be interesting to explore in more detail the motivations for the answers given, but the information obtained through the two apps allows this only to a limited degree. Perception is a complex and dynamic process that differs between individuals. It is influenced by a wide variety of internal and external factors (Bickerstaff \& Walker, 2001). Several studies have found a positive correlation between age, gender, education and socio-economic background to $A Q$ perception (Bickerstaff \& Walker, 2001; Brody et al., 2004; Deguen et al., 2017; Forsberg, Stjernberg, \& Wall, 1997; Howel, Moffatt, Prince, Bush, \& Dunn, 2002; Pantavou et al., 2017; Schmitz et al., 2018). Studies by Piro, Madsen, Næss, Nafstad, and Claussen (2008) on the other hand showed that there was no significant relationship between the perception of $A Q$ and factors such as age, education, and gender. For the CityAir users, we cannot confirm significant dependencies of perception on gender or education level. The difference between perception in different age classes is rather weak, possibly due to the low number of observations for some classes. Additional determinants for perception, such as health (i.e., people with poorer health often report $A Q$ to be worse than those with better health; see Howel, Moffatt, Bush, Dunn, \& Prince, 2003; Orru, Nordin, Harzia, \& Orru, 2018; Schmitz et al., 2018) or general concern about the environment and $A Q$ in particular (studies show that people that are generally concerned about $A Q$ seem to perceive $A Q$ as worse than it actually is, even though objective $A Q$ monitoring data shows that the $A Q$ has improved; see Mally, 2016; Oltra \& Sala, 2018; Schmitz et al., 2018), cannot be explored due to missing information about these factors.

$A Q$ perception can also be shaped by the area of residence, source of pollution and thermal sensation (Huang, Rao, van der Kuijp, Bi, \& Liu, 2017; Pantavou et al., 2017). In general, people more likely perceive air pollution when they can see dust, hear traffic and see exhaust fumes, rather than when it cannot be sensed through visual and sensory feedback (Gatersleben \& Uzzell, 2000;

Table 2. p-value matrices of non-parametric pairwise Wilcoxon Rank Sum tests for the data shown in Figure 9.

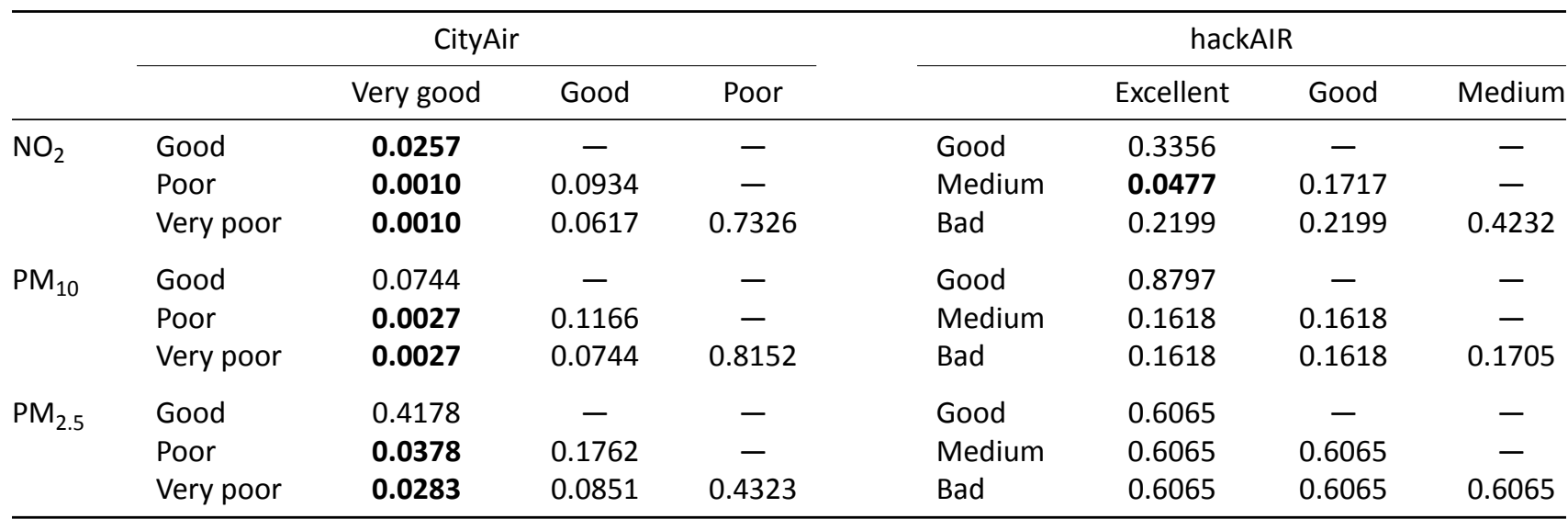

Notes: Difference between class medians that are statistically significant at the 0.95 level are marked in bold. The $p$-values were adjusted for multiple comparisons using the Benjamini and Hochberg (1995) method. 
Pantavou et al., 2018). For the CityAir app, we found indications that the physical experience of air pollution in spring (i.e., road dust, salt and gravel from the winter) could have led to a higher reporting rate of worse $A Q$ perception.

The fact that the overall judgement of $A Q$ in the greater Oslo area was rather positive could also be attributed to the so called 'Halo Effect.' This phenomenon describes the tendency of people who live in a polluted area to neglect the risks of air pollution in those areas where they live and work (Brody et al., 2004). The reluctance of people living in urban areas to recognise poor $A Q$ in their local environment shows that people's perception is not only dependent on technical risks, but also on factors such as trust (e.g., towards governments and regulatory institutions), political or economic empowerment and democratic processes, cultural factors and worldviews (Bickerstaff, 2004; Bickerstaff \& Walker, 2001).

Another potential reason for a bias in perceived $A Q$ compared to $A Q$ measurements could be related to media activities. Media has the potential to influence people's perception of risks, not necessarily through creating opinions about risks or shaping risk perception, but rather through shaping 'the societal experience with risk' (Cologna, Bark, \& Paavola, 2017; Renn, 2008). Thus, media's intention and the way stories are told can be quite influential for people's risk perception (Sharp, Jaccard, \& Keith, 2009). The influence of the media in the usage of the CityAir and the hackAIR app is demonstrated by increased reporting activities during social media events and after publication of newspaper articles.

However, without any additional information at hand, it is impossible to draw conclusions about the motivation or factors leading to the submission of a particular perception marker for both the CityAir and the hackAIR app.

The second focus of this article is to compare the perception data obtained through the two smartphone apps with objective data on AQ. We carried out a comparison of the perceived $A Q$ data against the output from a highresolution urban AQ model EPISODE (Hamer et al., 2019). The results indicated a positive association between the average modelled pollutant concentrations and the perception reports. The CityAir app data showed a statistically stronger correlation with the $A Q$ model than the ones from the hackAIR app. This can to some extent be related to the number of observations - the volume of the data from the hackAIR app is only two thirds of those from the CityAir app, thus, the relationship is weaker.

Our results indicate that the use of VGI for reporting of personal perception may prove to be of value in different respects. It could facilitate collection of a large amount of location specific data from people across different backgrounds and is not only limited to $A Q$ or other kinds of environmental monitoring. This offers the potential to provide researchers with large data sets on indications of environmental quality in places not directly covered by monitoring. Our results indicate that the percep- tion is associated with actual pollution levels, and this again provides higher credibility for data collected for new hotspots.

Mobile apps like CityAir or hackAIR are low-threshold tools that enable collection of large volumes of environmental information from the public. The use of VGI through apps such as CityAir or hackAIR could provide citizens with tools for democratisation. However, several issues need to be solved for the apps to be useful in practice, not least the recruitment of users. Despite the efforts to recruit, we have only recruited a very small percentage of the Oslo population. Willingness to engage with this kind of information sharing can be subject to the same underlying factors as the individual perception and would have to be further considered in a large-scale reporting experiment.

Tools like the CityAir and the hackAIR app may be suitable to support urban planning processes, providing citizens with a voice about their own perception and experiences for their neighbourhood or city. Citizens' involvement using VGI approaches in urban planning is already happening (e.g., Maptionnaire [Kahila \& Broberg, 2017]), although not on a large scale. Many tools exist for participatory urban planning, e.g., the use of the public participation GIS (PPGIS) in urban planning (Bugs, 2012), Urban Geo-Wiki for improving urban land cover (See et al., 2013), the Urban Analysis Kit for crowd-creative urban design (Mueller, Lu, Chirkin, Klein, \& Schmitt, 2018), and the ChangeExplorer for generating citizen involvement in local planning processes (Wilson, Tewdwr-Jones, \& Comber, 2019). It seems that PPGIS has the transformative power to empower citizens to voice their different opinions. However, challenges such as effective engagement, recruitment of a broad spectrum of people and coproduction of high-quality knowledge exchanges with actual effects on urban policy making still remain an issue (Brown \& Kytta, 2014). Since apps like CityAir and hackAIR do not have the capacity to resolve these challenges, they still could be used as a 'light' complement for tools that do not include any other VGI approaches. This would strengthen citizens' voices and contacts between urban planners, decision-makers and citizens.

We observed that reports on perceived $A Q$ indicate a relationship between average modelled pollutant concentrations in Oslo and the perception data. Thus, the application of VGI approaches to learn about citizens' perception of $A Q$ should be used further in urban development to promote participation, transparency and credibility. Nevertheless, it has to be ensured that uptake by authorities is actually happening and that the citizens participating in the VGI reporting also receive feedback about the results and the uptake of their data.

\section{Conclusion}

The CityAir and hackAIR apps were designed to get feedback on perceived $A Q$ over a longer time period and at different geographic locations within the larger Oslo area. 
The apps were not intended to investigate the motives behind urban $A Q$ perception ratings, but to provide citizens with a voice. $A Q$ in Oslo is most of the time below the limit values for the three pollutants studied here. The majority of the people that used the CityAir and hackAIR app perceived the $A Q$ in the greater Oslo area as good. Where they perceived $A Q$ as worse, the reference measurements often showed values below the limit values for the three major air pollutants $\left(\mathrm{NO}_{2}, \mathrm{PM}_{10}, \mathrm{PM}_{2.5}\right)$. However, overall, the classes of perceived $A Q$ showed associations with long-term average estimates. This indicates that the spatial patterns of perceived $A Q$ match those estimated on the basis of dispersion processes. Modelling is currently the only way to provide $A Q$ data with high spatial granularity. It is likely that perceived $A Q$ also matches the typical temporal patterns of $A Q$ (e.g., diurnal, weekly and seasonal cycles), however due to the relatively low number of reports available, we could not evaluate this within this study.

Environmental decision making including urban development should be a participatory process, embedding also people's perception of the environment and giving them the opportunity to express both positive views and concerns. Urban planning will certainly benefit from including public perception research as a tool to better understand socio-cultural dimensions and the beliefs and emotions that shape risk perception. The application of VGI approaches will allow citizen engagement and provide information on how people feel about their urban environment. This approach will provide more participation, transparency and credibility in urban planning processes and has a potential that should be investigated further.

\section{Acknowledgments}

The CityAir app was developed in the CITI-SENSE-Mob (2015-2016) project co-funded by the European Mobile and Mobility Industries Alliance. It was further developed and used in the CITI-SENSE project (2012-2016) that has received funding from the European Union's Seventh Framework Programme for research, technological development and demonstration under grant agreement No. 308524. The hackAIR app was developed and used in the hackAIR project (2016-2018) that has received funding from the European Union Horizon 2020 Research and Innovation Programme under grant agreement No. 688363. The authors would like to thank Dr. Stephen Matthew Platt for proofreading this article.

\section{Conflict of Interests}

The authors declare no conflict of interest.

\section{References}

Benjamini, Y., \& Hochberg, Y. (1995). Controlling the false discovery rate: A practical and powerful ap- proach to multiple testing. Journal of the Royal Statistical Society Series B, 57, 289-300.

Bickerstaff, K. (2004). Risk perception research: Sociocultural perspectives on the public experience of air pollution. Environment International, 30, 827-840.

Bickerstaff, K., \& Walker, G. (2001). Public understandings of air pollution: The 'localisation' of environmental risk. Global Environmental Change, 11, 133-145.

Brody, S. D., Peck, B. M., \& Highfield, W. E. (2004). Examining localized patterns of air quality perception in Texas: A spatial and statistical analysis. Risk Analysis, 24, 1561-1574.

Brown, G., \& Kytta, M. (2014). Key issues and research priorities for public participation GIS (PPGIS): A synthesis based on empirical research. Applied Geography, 46, 126-136.

Bugs, G. (2012). Assessment of online PPGIS study cases in urban planning. In B. Murgante, O. Gervasi, S. Misra, N. Nedjah, A. M. A. Coutinho Rocha, D. Taniar, B. O. Apduhan (Eds.), Computational science and its applications: ICCSA 2012. Lecture notes in computer science (Vol. 7333, pp. 477-490). Berlin and Heidelberg: Springer.

Castell, N., Dauge, F. R., Schneider, P., Vogt, M., Lerner, U., Fishbain, B., . . . Bartonova, A. (2017). Can commercial low-cost sensor platforms contribute to air quality monitoring and exposure estimates? Environment International, 99, 293-302.

Castell, N., Schneider, P., Grossberndt, S., Fredriksen, M. F., Sousa-Santos, G., Vogt, M., \& Bartonova, A. (2018). Localized real-time information on outdoor air quality at kindergartens in Oslo, Norway using low-cost sensor nodes. Environmental Research, 165, 410-419.

Cologna, V., Bark, R. H., \& Paavola, J. (2017). Flood risk perceptions and the UK media: Moving beyond "once in a lifetime" to "be prepared" reporting. Climate Risk Management, 17, 1-10. https://doi.org/ 10.1016/j.crm.2017.04.005

Deguen, S., Padilla, M., Padilla, C., \& Kihal-Talantikite, W. (2017). Do individual and neighbourhood characteristics influence perceived air quality? International Journal of Environmental Research and Public Health, 14, 1559-1578.

European Commission. (2017). Special Eurobarometer 468 "Attitudes of European citizens towards the environment." Brussels: Directorate-General for Communication.

European Environmental Agency. (2018). Air quality in Europe: 2018 report (No 12/2018). Luxembourg: Publications Office of the European Union.

Forsberg, B., Stjernberg, N., \& Wall, S. (1997). People can detect poor air quality well below guideline concentrations: A prevalence study of annoyance reactions and air pollution from traffic. Occupational and Environmental Medicine, 54, 44-48.

Gatersleben, B., \& Uzzell, D. (2000). The risk perception of transport-generated air pollution. IATSS Research, 24, 30-38. 
Gulia, S., Nagendra, S. M. S., Khare, M., \& Khanna, I. (2015). Urban air quality management: A review. Atmospheric Pollution Research, 6, 286-304.

Hamer, P. D., Walker, S.-E., Sousa-Santos, G., Vogt, M., VoThanh, D., López-Aparicio, S., . . Karl, M. (2019). The urban dispersion model EPISODE-Part 1: A Eulerian and subgrid-scale air quality model and its application in Nordic winter conditions. Geoscientific Model Development. Manuscript submitted for publication.

Howel, D., Moffatt, S., Bush, J., Dunn, C. E., \& Prince, H. (2003). Public views on the link between air pollution and health in Northeast England. Environmental Research, 91, 163-171.

Howel, D., Moffatt, S., Prince, H., Bush, J., \& Dunn, C. E. (2002). Urban air quality in north-east England: Exploring the influences on local views and perceptions. Risk Analysis, 22, 121-130.

Huang, L., Rao, C., van der Kuijp, T. J., Bi, J., \& Liu, Y. (2017). A comparison of individual exposure, perception, and acceptable levels of $\mathrm{PM}_{2.5}$ with air pollution policy objectives in China. Environmental Research, 157, 78-86.

Kahila, M., \& Broberg, A. (2017). Making cities wiser: Crowdsourcing for better decisions. International Federation of Surveyors. Retrieved from https:// www.fig.net/resources/monthly_articles/2017/ kahila_etal_may_2017.asp

Kosmidis, E., Syropoulou, P., Tekes, S., Schneider, P., Spyromitros-Xioufis, E., Riga, M., . . . Alexandri, G. (2018). hackAIR: Towards raising awareness about air quality in Europe by developing a collective online platform. ISPRS International Journal of Geo-Information, 7(5). https://doi.org/10.3390/ ijgi7050187

Lisjak, J., Schade, S., \& Kotsev, A. (2017). Closing data gaps with citizen science? Findings from the Danube region. ISPRS International Journal of GeoInformation, 6, 277-297.

Liu, H.-Y., Kobernus, M., Broday, D., \& Bartonova, A. (2014). A conceptual approach to a citizens' observatory: Supporting community-based environmental governance. Environment Health, 13, 107-120.

Liu, H.-Y., Schneider, P., Haugen, R., \& Vogt, M. (2019). Performance assessment of a low-cost PM2.5 sensor for a near four-month period in Oslo, Norway. Atmosphere, 10(2), 41-59.

López-Aparicio, S., Vogt, M., Schneider, P., Kahila-Tani, M., \& Broberg, A. (2017). Public participation GIS for improving wood burning emissions from residential heating and urban environmental management. Journal of Environmental Management, 191, 179-188.

Mahajan, S., Kumar, P., Pinto, J. A., Riccetti, A., Schaaf, K., Camprodon, G., . . . Forino, G. (2020). A citizen science approach for enhancing public understanding of air pollution. Sustainable Cities and Society, 52, 101800.

Mally, K. V. (2016). Perceptions of air quality in Ljubljana. Dela, 46, 77-88.
Mayer, A., O'Connor Shelley, T., Chiricos, T., \& Gertz, M. (2017). Environmental risk exposure, risk perception, political ideology and support for climate policy. Sociological Focus, 4, 309-328.

Mueller, J., Lu, H., Chirkin, A., Klein, B., \& Schmitt, G. (2018). Citizen design science: A strategy for crowdcreative urban design. Cities, 72, 181-188.

Oltra, C., \& Sala, R. (2018). Perception of risk from air pollution and reported behaviors: A cross-sectional survey study in four cities. Journal of Risk Research, 7, 869-884.

Orru, K., Nordin, S., Harzia, H., \& Orru, H. (2018). The role of perceived air pollution and health risk perception in health symptoms and disease: A population-based study combined with modelled levels of PM10. International Archives of Occupational and Environmental Health, 91, 581-589.

Pantavou, K., Lykoudis, S., \& Psiloglou, B. (2017). Air quality perception of pedestrians in an urban outdoor Mediterranean environment: A field survey approach. Science of the Total Environment, 574, 663-670. http://dx.doi.org/10.1016/j.scitotenv. 2016.09.090

Pantavou, K., Psiloglou, B., Lykoudis, S., Mavrakis, A., \& Nikolopoulos, G. N. (2018). Perceived air quality and particulate matter pollution based on field survey data during a winter period. International Journal of Biometeorology, 62, 2139-2150.

Piro, F. N., Madsen, C., Næss, Ø., Nafstad, P., \& Claussen, B. (2008). A comparison of self reported air pollution problems and GIS-modeled levels of air pollution in people with and without chronic diseases. Environmental Health, 7, 9-19. https://doi.org/10.1186/ 1476-069X-7-9

Renn, O. (2008). Risk governance: Coping with uncertainty in a complex world. London: Earthscan.

Schmitz, S., Weiand, L., Becker, S., Niehoff, N., Schwartzbach, F., \& von Schneidemesser, E. (2018). An assessment of perceptions of air quality surrounding the implementation of a traffic-reduction measure in a local urban environment. Sustainable Cities and Society, 41, 525-537.

Schneider, P., Bartonova, A., Castell, N., Dauge, F. R., Gerboles, M., Hagler, G. S. W., ... Williams, R. W. (2019). Toward a unified terminology of processing levels for low-cost air-quality sensors. Environmental Science \& Technology, 53(15), 8485-8487.

Schneider, P., Castell, N., Dauge, F. R., Vogt, M., Lahoz, W. A., \& Bartonova, A. (2018). A network of lowcost air quality sensors and its use for mapping urban air quality. In G. Bordogna \& P. Carrara (Eds.), Mobile information systems leveraging volunteered geographic information for Earth observation (pp. 93-110). Berlin: Springer International Publishing.

Schneider, P., Castell, N., Vogt, M., Dauge, F. R., Lahoz, W. A., \& Bartonova, A. (2017). Mapping urban air quality in near real-time using observations from low-cost sensors and model information. Environment Inter- 
national, 106, 234-247.

See, L., Fritz, S., Perger, C., Van der Velde, M., Albrecht, F., McCallum, I., . . . Schill, C. (2013). Urban GeoWiki: A crowdsourcing tool for improving urban land cover. In C. N. Silva (Ed.), Citizen e-participation in urban governance: Crowdsourcing and collaborative creativity (pp. 119-143). Hershey, PA: IGI Global.

Sharp, J. D., Jaccard, M. K., \& Keith, D. W. (2009). Anticipating public attitudes toward underground $\mathrm{CO} 2$ storage. International Journal of Greenhouse Gas Control, 3, 641-651.

Sîrbu, A., Becker, M., Caminiti, S., de Baets, B., Elen, B., Francis, L., . . . Van den Bossche, J. (2015). Participatory patterns in an international air quality monitoring initiative. PLOS ONE, 10(8). https://doi.org/ 10.1371/journal.pone.0136763

Spyromitros-Xioufis, E., Moumtzidou, A., Papadopoulos, S., Vrochidis, S., Kompatsiaris, Y., Georgoulias, A. K., ... Kourtidis, K. (2018). Towards improved air quality monitoring using publicly available sky images. In A. Joly, S. Vrochidis, K. Karatzas, A. Karppinen, \& P. Bonnet (Eds.), Multimedia tools and applications for environmental and biodiversity informatics: Mul- timedia systems and applications (pp. 67-92). Cham: Springer.

Turrini, T., Dörler, D., Richter, A., Heigl, F., \& Bonn, A. (2018). The threefold potential of environmental citizen science: Generating knowledge, creating learning opportunities and enabling civic participation. Biological Conservation, 225, 176-186. https://doi. org/10.1016/j.biocon.2018.03.024

Wesseling, J., de Ruiter, H., Blokhuis, C., Drukker, D., Weijers, E., Volten, H., \& Tielemans, E. (2019). Development and implementation of a platform for public information on air quality, sensor measurements, and citizen science. Atmosphere, 10, 445-465.

Wilson, A., Tewdwr-Jones, M., \& Comber, R. (2019). Urban planning, public participation and digital technology: App development as a method of generating citizen involvement in local planning processes. Environment and Planning B: Urban Analytics and City Science, 46(2), 286-302.

World Health Organization. (2016). Ambient (outdoor) air quality and health. Geneva: World Health Organization. Retrieved from http://www.who.int/ mediacentre/factsheets/fs313/en

\section{About the Authors}

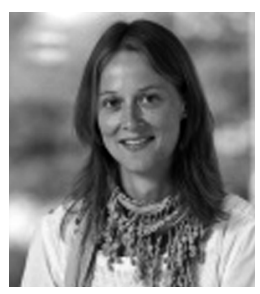

Sonja Grossberndt holds a MSc in Health Promotion and Management and has been working as Scientist at NILU-Norwegian Institute for Research for more than 10 years. She has developed an interest in engaging with the public, both through science communication and citizen science activities. Sonja's current research focuses on citizen science activities in air quality monitoring, investigating the engagement of different groups, such as school children, public administrations and people interested in the topic.

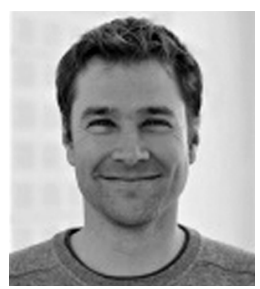

Philipp Schneider is a Senior Research Scientist at NILU. He received his PhD in 2008 from the University of California-Santa Barbara focusing on satellite remote sensing and geospatial data analysis. Subsequently he held a position as Postdoctoral Research Scientist at NASA's Jet Propulsion Laboratory and the California Institute of Technology. Philipp has more than 15 years of experience with geospatial data analysis with a particular emphasis on the use of satellite data for various environmental applications.

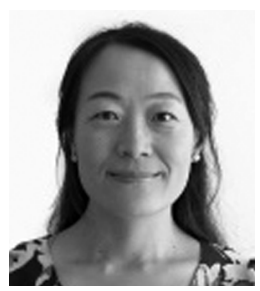

Hai-Ying Liu is a Senior Scientist at the Department of Environmental Impacts and Sustainability, NILU. She holds a PhD in Ecology from University of Oslo and has expertise on air pollution exposure assessment, environmental sustainability, citizens' observatories and integrative approaches to environmental issues as well as exploitation of low-cost micro-sensors of air quality for various applications. Her current research interests include nature-based solutions for improving health and well-being, citizen science for raising environmental awareness, and urban sustainable development.

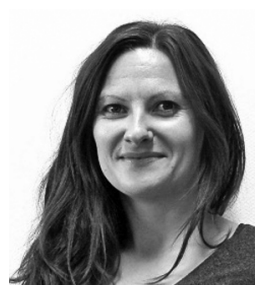

Mirjam F. Fredriksen is a Senior System Developer with BSc in Information Technologies. She has over 10 years of experience in developing information systems for the Norwegian Institute for Air Research, from high quality air quality monitoring systems, GIS visualizations to research on distributed file systems for loT platforms and smartphone applications for user awareness and information. The last years she has also taken the leadership for software development in large environmental projects, such as for the CityAir app in the EU FP7 CITI-SENSE project. 

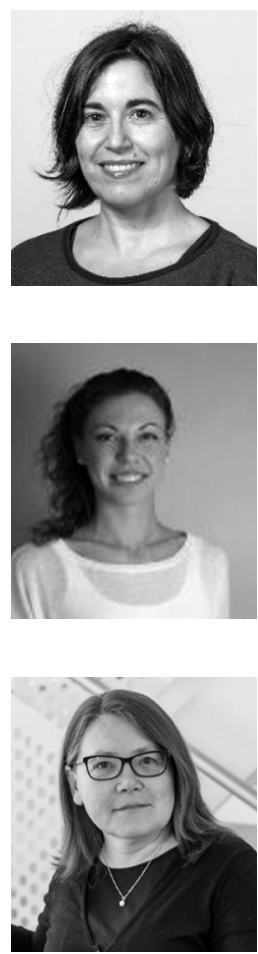

Alena Bartoňová (PhD) has background in mathematical statistics and environmental sciences. Her research interests include exposure science, air quality monitoring and assessment, environmental health impact assessment and science-policy-public interface. Alena promotes in her research high levels of interdisciplinary collaboration and involvement of the public. She has led several interdisciplinary projects co-funded by the European Union, with partners from environmental sciences, life sciences, technology and social sciences. 